\title{
CALCULATIONS OF THE CONTROLLER LOAD IN COMPUTER CONTROL NETWORK USING PROBABILITY THEOREM
}

\author{
M. Z. El-Sadek \\ Electrical Engineering Department, Assiut University, Assiut, Egypt \\ M. A. Abdlwahab \\ Electrical Engineering Department, Minia University, Minia, Egypt

\section{A. A. Alkosy} \\ Electrical Engineering Department, Cairo University, Cairo, Egypt
}

\section{A. M. Hemeida}

Electrical Engineering Department, Higher Institute of Energy Aswan, Egypt

\section{S. A. Younies}

Aswan Hydro Power Plant, Aswan, Egypt

(Received September 17, 2008 Accepted October 29, 2008)

\begin{abstract}
This paper presents the calculation of the controller load of computer control network in a real system. The Calculation of the controller load is very important in order to aid the designer engineer to choose the suitable capacity of the controller for data size. The probability theorem is used to investigate the process of load calculation. The interpolation technique is used to get the function of the required data for the studied system. The calculated value is compared with the measured value to investigate the reality of the proposed method in calculating the load controller using probability theorem. The comparative study between the measured value and calculated value indicate the efficiency of the proposed technique.
\end{abstract}

KEYWORDS: Distributed Control System - Controller Load Probability Theorem.

\section{INTRODUCTION}

In recent years the computer control technology has developed greatly with the rapid enhancement. The development of the computer technologies reflects to other fields such as control theory and data communication network. The main stream is so called distributed control systems, DCS. Since 1970s the DCS has been used widely in industry, in many applications [1-4]. The distributed control system, DCS has a different data forms such as analog input, analog input calculated, analog output, analog out calculated, digital input, digital input calculated and digital output [5]. The data come from the field all has one of the previous forms to the controller sub-rack then through a communication to the controller rack. These data will be processed on the processor according to the required functions, subjected to the software program. Let's go through to explain briefly the field data which applied to the controller.

\section{CONTROLLER LOAD CALCULATIONS}

The controller load is monitored as a percentage from the total capacity of the controller. The capacity of the controller is measured and calculated as bits/sec for the 
same studied high dam controller system. In order to calculate the load of the controller in this paper, this should be done on the high dam network as a life network. The data of this network as analog, digital or events will be used in load calculation. Being these data have a different forms and the system is working hot all the time, it should be subjected to the probability theorem in the dynamic part of the controller load. Finally the load of the high dam controller will be calculated according to the high dam data base dynamics.

\subsection{General Controller (CPU) Load Equations}

For the controller used in the computer control network such as power stations, production lines in the factories, and a unified power system, the load consists of static part and dynamic part. But in the telephone system as example the load is only the subscriber's requests and it is considered as a dynamic load, beside the internal activities of the CPU. In the control network there are many data forms. The forms of data in control network are:

- AI (analog input)

- AIC (analog input calculated)

- AO (analog output)

- AOC (analog output calculated)

- DI (digital input .....Cyclic or interrupt)

- DIC (digital input calculated)

- DOC (digital output calculated)

Based on these data we can estimate a formula for the controller (CPU) load used in the control fields through, distributed control system, DCS networks.

These types of the controllers are subjected to static load which will be determined from specification's tables supplied by the manufacturers. These tables are shown in Appendices A,B for the studied system of the controller used in the high dam power plant computer network. This controller is $\mathrm{ABB}$ made with a module name (AC450).

The static load is subjected to a certain scan time which should be optimized to give a stable performance. The base load has a fixed value according to manufacture's instructions. But the dynamic load is referred to the system dynamics and data activities applied to the controller.

The load of the controller contains briefly 3 parts:

1- The load used to cover the controller internal activities named the base load.

2- The static load due to the scanning process of the data designed through the software.

3- The dynamic load due to data variations, system dynamics and operator requests.

The load of the controller can be expressed in the following form.

Load $=$ base load + static load + dynamic load

\subsection{Static Load Calculations}

The static load will be calculated using the tables in the appendices A, B below. It is calculated for $A_{I}, A I C, A_{0}$, DIC, and Do. These data base are explained in details above. 


\subsection{Analog Input (AI) Static Load}

From the appendices A, B the analog input data base element can be summarized in the following tables. This can be seen from the sequence of the calculations mentioned in appendices A, B.

Table (1) analog input load calculation

\begin{tabular}{|c|c|c|c|c|c|c|}
\hline serial & program & NO of data & $\begin{array}{c}\text { Scan time } \\
(\mathrm{ms})\end{array}$ & $\begin{array}{c}\text { service time } \\
(\mathrm{ms})\end{array}$ & $\begin{array}{c}\text { Load } \\
\%\end{array}$ & sum \\
\hline 1 & PC1.1 & 8 & 50 & 0.2 & 3.2 & \\
\hline 2 & PC4.4 & 13 & 50 & 0.2 & 5.2 & \\
\hline 3 & PC14.1 & 40 & 200 & 0.2 & 4 & \\
\hline 4 & PC31.4 & 99 & 500 & 0.2 & 3.96 & \\
\hline 5 & PC32.1.4 & 56 & 500 & 0.2 & 2.24 & \\
\hline 6 & PC54.1 & 111 & 500 & 0.2 & 4.44 & \\
\hline 7 & PC54.3 & 116 & 500 & 0.2 & 4.64 & \\
\hline 8 & & & & & & 27.68 \\
\hline
\end{tabular}

\subsection{Analog Input Calculated Static Load}

Using the appendices A, B and data base movements, the calculations appear in Table 2. This table depicts the load for each PC then all items should be summed to give the total load.

Table (2) Analog input calculated load

\begin{tabular}{|c|c|c|c|c|c|c|}
\hline serial & program & No of data & $\begin{array}{c}\text { Scan time } \\
(\mathrm{ms})\end{array}$ & $\begin{array}{c}\text { service time } \\
(\mathrm{ms})\end{array}$ & $\begin{array}{c}\text { Load } \\
\%\end{array}$ & sum \\
\hline 1 & PC3.2 & 39 & $200 \mathrm{~ms}$ & 0.003 & .0585 & \\
\hline 2 & PC4.1 & 74 & $200 \mathrm{~ms}$ & 0.003 & 0.111 & \\
\hline 3 & PC4.2 & 40 & $200 \mathrm{~ms}$ & 0.003 & 0.06 & \\
\hline 4 & PC4.3 & 0 & $200 \mathrm{~ms}$ & 0.003 & 0 & \\
\hline 5 & PC31.1 & 66 & $500 \mathrm{~ms}$ & 0.003 & 0.0396 & \\
\hline 6 & PC31.4 & 83 & $500 \mathrm{~ms}$ & 0.003 & 0.0498 & \\
\hline 7 & PC32.1 & 83 & $500 \mathrm{~ms}$ & 0.003 & 0.0498 & \\
\hline 8 & PC52.1 & 83 & $500 \mathrm{~ms}$ & 0.003 & 0.0498 & \\
\hline 9 & PC54.3 & 81 & $500 \mathrm{~ms}$ & 0.003 & 0.0486 & \\
\hline 10 & & & & & & 0.467 \\
\hline
\end{tabular}

\subsection{Analog Output Static Load}

The same procedure of section $(3.3),(3,4)$ is also used to calculate the load of analog output and the results appear in Table 3.

Table (3) analog output static load

\begin{tabular}{|c|c|c|c|c|c|c|}
\hline serial & program & No of data & $\begin{array}{c}\text { Scan time } \\
(\mathrm{ms})\end{array}$ & $\begin{array}{c}\text { service time } \\
(\mathrm{ms})\end{array}$ & $\begin{array}{c}\text { Load } \\
\%\end{array}$ & sum \\
\hline 1 & PC4.5.1 & 13 & $200 \mathrm{~ms}$ & 0.02 & 0.13 & \\
\hline 2 & & & & & & 0.13 \\
\hline
\end{tabular}




\subsection{Digital Input Calculated Static Load}

Table (4) shows the static load of the digital input calculated using the same procedure from appendices $\mathrm{A}, \mathrm{B}$.

Table (4) digital input calculated static load

\begin{tabular}{|c|c|c|c|c|c|c|}
\hline serial & Program & No of data & $\begin{array}{c}\text { Service } \\
\text { time }(\mathrm{ms})\end{array}$ & $\begin{array}{c}\text { Scan } \\
\text { time }(\mathrm{ms})\end{array}$ & Load\% & sum \\
\hline 1 & PC2.1 & 36 & 0.003 & $50 \mathrm{~ms}$ & 0.216 & \\
\hline 2 & PC4.1,2 & 51 & 0.003 & $200 \mathrm{~ms}$ & 0.0765 & \\
\hline 3 & Pc32,PC54 & 44 & 0.003 & $500 \mathrm{~ms}$ & 0.0264 & \\
\hline & & & & & & 0.32 \\
\hline
\end{tabular}

\subsection{Digital Output Static Load}

The digital output static load results can be calculated using same procedure as shown in Table (5).

Table (5) digital output static load

\begin{tabular}{|c|c|c|c|c|c|c|}
\hline serial & Program & $\begin{array}{c}\text { NO of } \\
\text { data }\end{array}$ & $\begin{array}{c}\text { Scan time } \\
(\mathrm{ms})\end{array}$ & $\begin{array}{c}\text { service } \\
\text { time(ms) }\end{array}$ & $\begin{array}{c}\text { Load } \\
\%\end{array}$ & sum \\
\hline 1 & PC1.9.2 & 34 & $200 \mathrm{~ms}$ & 0.003 & 0.05 & \\
\hline 2 & PC52.1 & 16 & $500 \mathrm{~ms}$ & 0.003 & 0.0096 & \\
\hline 3 & & & & & & 0.0596 \\
\hline
\end{tabular}

Note that the data base elements $\mathrm{D}_{\mathrm{I}}$, DOC, AOC can't be calculated because $\mathrm{D}_{\mathrm{I}}$ (digital input) in the studied system high dam control network is specified as interrupt; this means it will be applied to the controller when it changes its position. For the DOC and AOC are not found in the high dam control network.

\subsection{Total Static Load}

The total static load $=27.68+0.467+0.13+0.32+0.0576=\mathbf{2 8 . 6 5} \%$

\subsection{Dynamic Load Calculations}

As mentioned above the dynamic load is raised from the system dynamics like starting of the generators, load increase, load decrease, and switch on/off of the breakers also the operator screen requests. In order to calculate the dynamics of the control system we have to consider the probability theory and probability functions as the following sections.

\section{PROBABILITY THEOREMS FOR CONTROLLER INPUT SIGNALS}

The nature of the data applied to the controller in the control system is:

- Continuous data form (analog)

- Discrete data form (Digital)

For the discrete data base the following mathematical formulas will be used to calculate the probability for digital signals are: 


\subsection{Discrete signals}

$$
\begin{aligned}
& F(x) \geq 0 \\
& \sum_{\mathrm{X}} F(x)=1
\end{aligned}
$$

The equation for discrete (digital) signals in a certain time period will be:

$$
P_{n}=(\lambda t)^{n} * e^{-\lambda t} / n !
$$

Where; $\mathrm{P}_{\mathrm{n}}=$ Digital input probability (discrete) in a certain period of time $(\mathrm{t})$.

Based on the above equations the probabilities of the discrete data base can be calculated as the following.

Let $\mathrm{P}(\mathrm{t})$ be the probability of one count in time $\mathrm{t}$, so that $\mathrm{P}(\mathrm{t}+\Delta \mathrm{t})$ is the probability of one count in time $t+\Delta t$ Now we will have one count in time $t+\Delta t$ in the following two mutually exclusive cases:

(i) $\quad 1$ count in time $\mathrm{t}$ and 0 counts in time $\Delta \mathrm{t}$

(ii) 0 counts in time $t$ and 1 count in time $\Delta t$

The probability of (i) is $\mathrm{P}_{1}(\mathrm{t})(1-.(\mathrm{t} \Delta \mathrm{z}$

The probability of (ii) is $P_{O}(t): \Delta t$.

Thus, apart from terms involving $(\Delta t)^{2}$ and higher.

$$
P_{1}(t+\Delta t)=P_{1}(t)(1-\lambda \Delta t)+P_{o}(t) \lambda \Delta t
$$

This can be written

$$
P_{1}(t+\Delta t)-p_{1}(t) / \Delta t=\Delta t-\lambda P_{1}(t)
$$

Taking the limit as $\Delta t \rightarrow 0$ and using the expression for $\mathrm{P}_{0}(\mathrm{t})=\mathrm{e}^{-\mathrm{t} \lambda}$

So: $\quad \frac{d P_{1}}{d t}=\lambda e^{-\lambda t}-\lambda P_{1}$

Or

$$
\begin{aligned}
& \frac{d p_{1}}{d t}=\lambda e^{-\lambda t}-\lambda P_{1} \\
& \frac{d p_{1}}{d t}+\lambda P_{1}=\lambda e^{-\lambda t}
\end{aligned}
$$

Multiplying by $\mathrm{e}^{- \text {-at }}$ this can be written

$$
\frac{d}{d t}\left(e^{\lambda t} P_{1}\right)=\lambda
$$

Which yields on integrating

$$
P_{1}(t)=\lambda t e^{-\lambda t}+c_{2} e^{-\lambda t}
$$

If $\mathrm{t}=0, \mathrm{P}_{1}(0)$ is the probability of 1 count in time 0 , which is zero. Using this in equation (10) we find $\mathrm{c}_{2}=0$. Thus

$$
P_{1}(t)=\lambda t e^{-\lambda t}
$$


By continuing in this manner we can show that the probability of $n$ counts in time $t$ is given by:

$$
P_{n}(t)=(\lambda t)^{n} * e^{-\lambda t} / n !
$$

This is the Poisson distribution.

The discrete data probability can be calculated using also the following formula.

$$
\text { Probability }=\lambda / N
$$

Where:

$-\quad s=$ number of events

- $\quad \mathrm{N}=$ sample space

\subsection{Analog Input Probability}

Matlab tools is used to evaluate the continues data probability

The formulas used in continues data evaluation are:

$$
\begin{aligned}
& F(X) \geq 0 \\
& \int_{-\infty}^{\infty} F(X) d x=1
\end{aligned}
$$

So the probability between $(a, b)$ limits will be expressed by the following equation.

$$
P(a<X<b)=\int_{a}^{b} F(X) d x
$$

The general equation for continues probability (analog input) and (analog input calculated) can be derived [7].

$$
P(a<x b)=C * \int_{b}^{a} f(x) d x=C[f(b)-f(a)]
$$

Where:

$$
C^{*} f(x)=1
$$

\subsection{Probability Calculations}

The above equations (12), and (17) are solved by Matlab software to find both the discrete and continues data base probability of the studied system. The final results are shown in Table (6).

\subsubsection{Continuous signals}

To calculate the probability of continues signals the Matlab software is used with the following steps.

1- The signal will be displayed as a trend from the DCS system.

2- Some points of coordinates should be located to represent the trend behavior of the analog element. 
3- From the coordinates the equation of the trend can be derived using the function (polyval) in matlab.

4- The resulted function for polynomial should be integrated.

5- Using the above functions the probability can be calculated.

6- For accuracy the probability will be calculated for a different cases and the mean value should be calculated.

\subsubsection{Discrete signals}

For discrete (digital input) signal, equation (12) which stated below as equation (18) should be used. The calculation of the probability will be carried out through matlab program using the following equation.

$$
P_{n}=(\lambda t)^{n} * e^{-\lambda t} / n !
$$

Where:

- $P_{n}=$ probability of the discrete signals.

- $\lambda \mathrm{t}=$ constant times the time sample space.

- $\quad \mathrm{n}=$ number of signals.

\subsubsection{Digital output probability:}

The digital output probability can be calculated from the field counts let's go to have a look on the counts at the point of the high events, that means during the generator start, generator stop and auxiliaries

The events will be as flows:

1 - Generator start sequence $=7$

2- Generator stop sequence $=10$

3- Auxiliaries operation. $=6$

Total number of events $=7+10+6=23$

Since probability $\mathrm{P}=\lambda / \mathbf{N}=23 / 76=0.302$

Where: $\lambda=$ number of events, $\mathrm{N}=$ sample space or total number of data base signals.

\subsubsection{Digital input calculated.}

The counting of digital input calculated signal also can be done from the field for the max point of load (start/stop) sequences of the generator the result will be as follows:

1- Standstill, on-line and stop enables (indication) $=6$.

2- Unit standstill, ready for synchronize and on-line (working mode) $=6$

3- High pump on high pressure $>50$ bar (indication) $=4$

4- Governor 4x-R-0, G P S (7\% and $0 \%$ ) working mode $=8$

5- Unit circuit breaker on/off (working mode) $=2$

6- MG field switch on/off and Aux AVR off (working mode) $=3$

Total events of DIC $=6+6+4+8+2+3=29$ events

The probability $\mathbf{P}=\lambda / \mathbf{N}=29 / 58=0.5$

The total results of the probability seen in table (6) below 
Table (6) calculated probability

\begin{tabular}{|c|c|c|}
\hline serial & Data base name & probability \\
\hline 1 & AI & 0.461 \\
\hline 2 & AIC & 0.403 \\
\hline 3 & Ao & 0.321 \\
\hline 4 & DI & 0.0327 \\
\hline 5 & DIC & 0.50 \\
\hline 6 & Do & 0.302 \\
\hline 7 & AOC & ------------ \\
\hline 8 & DOC & ----------- \\
\hline
\end{tabular}

\subsubsection{Dynamic load equation estimation:}

To estimate the dynamic load we have to refer to the probability theorems.

Dynamic load =

$$
\begin{aligned}
& P_{A I}^{*} N_{1}^{*} T_{1}+P_{A I C}^{*} N_{2}^{*} T_{2}+P_{A O}^{*} N_{3}^{*} T_{3}+P_{A O C}^{*} N_{4}^{*} T_{4}+P_{D I}^{*} N_{5}^{*} T_{5}+P_{D I C}^{*} N_{6} T_{6}+ \\
& P_{D O} * N_{7} T_{7}+P_{D O C} * N_{8}^{*} T_{8}
\end{aligned}
$$

Where:

- $\quad P^{\prime} s=$ are probabilities for the different data base forms.

- $\quad$ N's = number of data base elements for each kinds

- $\quad$ T's $=$ the service time's

\subsubsection{Dynamic load calculation:}

To solve equation of the dynamic load, let's consider the DCS system of the high dam power plant which use (AC450) controller, ABB manufacturing.

The dynamic load formula is as the following:

$$
\text { Load }(\text { dynamic })=P * N * T
$$

Where: $\mathrm{P}=$ probability, $\mathrm{N}=$ number of data base, $\mathrm{T}=$ service time.

The following table (7) shows the number of data base and the corresponding service time.

Table (7) service time and number data elements

\begin{tabular}{|l|l|c|l|}
\hline Serial & Data base & Number of data base & Service time \\
\hline $1-$ & AI & 182 & 0.15 \\
\hline $2-$ & AIC & 83 & 0.08 \\
\hline $3-$ & AO & 15 & 0.18 \\
\hline $4-$ & DI & 384 & 0.6 \\
\hline $5-$ & DIC & 58 & 0.05 \\
\hline $6-$ & DO & 76 & 0.13 \\
\hline $7-$ & AOC & ------------------------- & ----------------- \\
\hline $8-$ & DOC & ------------------------- & ----------------- \\
\hline
\end{tabular}




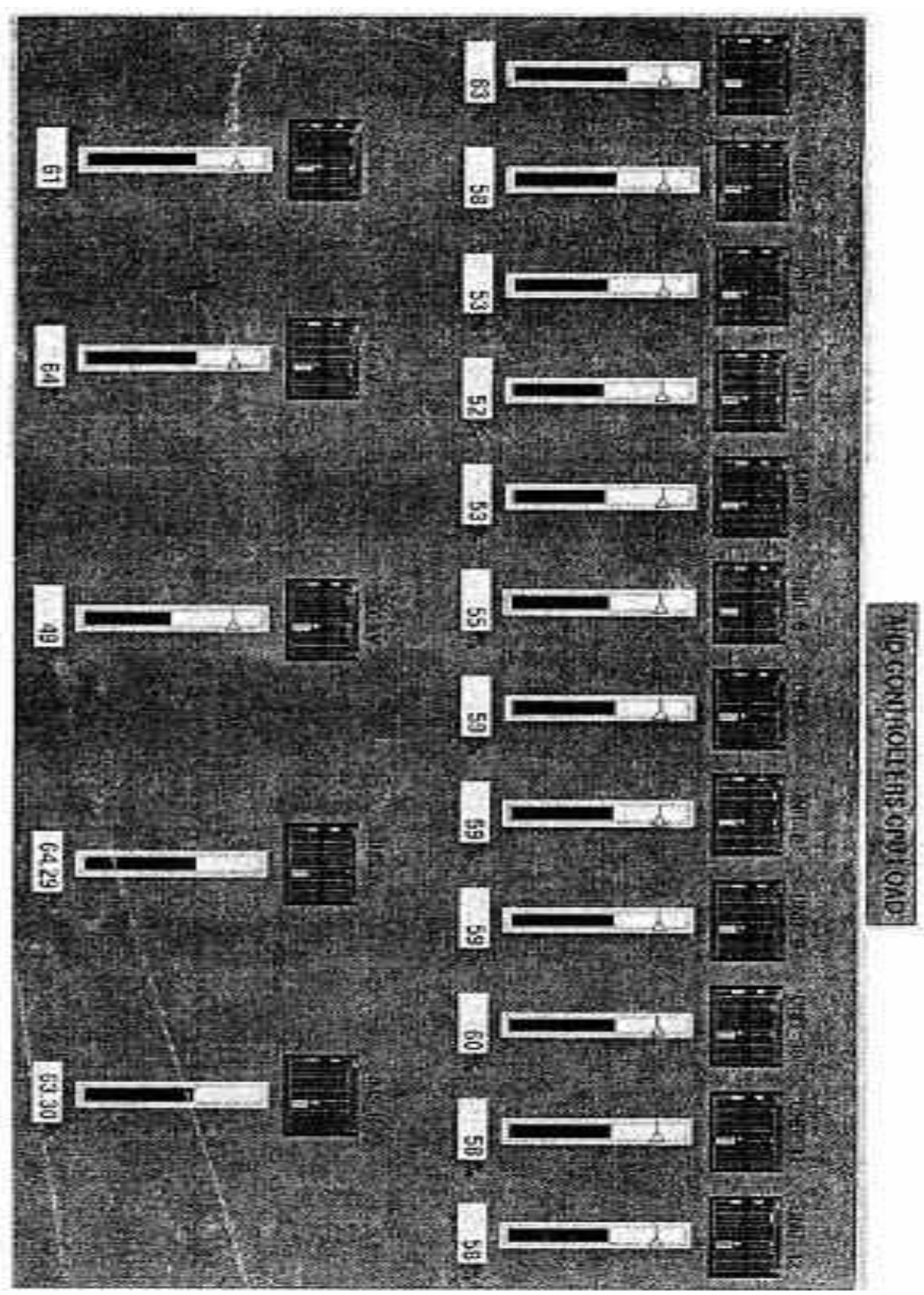

Fig. 1 The measured load of the controller for high dam

\subsubsection{Calculations of dynamic signals}

1 - $\mathrm{AI}=0.461 * 182 * 0.15=12.585$

2 - $\mathrm{AIC}=0.403 * 83 * 0.08=2.676$

$3-\mathrm{A}_{\mathrm{o}}=0.321 * 15 * 0.18=0.867$

4- $\mathrm{DI}=0.0327 * 0.6 * 384=7.534$

5- $\mathrm{DIC}=0.5 * 0.05 * 58=1.45$ 
6- Do $=0.302 * 0.13 * 76=2.98$

\section{Total dynamic load $=\mathbf{2 8 . 1}$}

Base load $=$ the value taken for our analysis is 2 from the controller features.

Static load $=34.875 \% \quad$ calculated using ABB instruction manuals.

Load total $=\mathbf{2 \%}+\mathbf{2 8 . 6 5 \%}+\mathbf{2 8 . 1} \%=\mathbf{5 8 . 7 5 \%}$

This load value should be $<80 \%$

The measured value of the controller load for the high dam power station is as shown in Fig. 1.

\section{CONCLUSIONS}

This paper presents the implementations of the probability theorem to calculate the dynamic load of the controller in a distributed control system for HIGH DAM in Aswan.

The measured value of the controller load in the studied real system of the High dam power station as shown in Fig. 1 is used to judge the efficiency of the proposed method. The probability theorem is used to calculate the controller dynamic load. The mathematical interpolation is used to derive the function of the trends comeing out from the information management system of the high dam computer controller network. The Matlab software is used for the calculation of the controller dynamic load based probability theory. The comparative studies between the measured and calculated values indicate the efficiency of the proposed method in the calculation of the controller load of the studied real system. These encourage using the proposed method for calculating the dynamic load of the controller for any DCS.

\section{REFERENCES:}

[1] Xing Jianchun, Wang Ping, Cheng Baoyi, Wang Shuangqing, and Yang Qiliang, "Field bus Based Distributed Control System" 2004 8th lnternatlonal Conference on Control, Automation, Robotics and Vision Kunming, China, 6-9th December 2004, pp. 1690-1694.

[2] Dean Craig and Craig Befus, "Implementation of a Distributed Control System for Electric Distribution Circuit Reconfiguration" Power Engineering Society General Meeting, 2005.

IEEE 12-16 June 2005 Page(s):2436 - 2441 Vol. 3.

[3] Georg Frey and Tanvir Hussain, "Modeling Techniques for Distributed Control Systems based on the IEC 61499 Standard - Current Approaches and Open Problems" Proceedings of the 8th International Workshop on Discrete Event Systems Ann Arbor, Michigan, USA, July 10-12, 2006.

[4] L. Samaranayake, "Delay Compensation, Design and Simulation of Controllers for Distributed Control Systems" First International Conference on Industrial and Information Systems, ICIIS 2006, 8 - 11 August 2006, Sri Lanka.

[5] El-Sadek, M.Z.; Hemeida, A.M.; Abelwahab, M.A.; Alkosy, A.; Younies, S.A. "Distributed control system approach for a unified power system" Int. Conference on Electrical, Electronic and Computer Engineering,2004.ICEEC'04.2004, 5-7 Sept. 2004 Page(s):947 - 950. 
[6] ABB Manuals adva command using (AC 450) controller.

[7] Murray R. Spiegel, ph. D, "Theory and problems of probability and statistics book 23rd printing 1998.

\section{Appendix (A)}

Advant ${ }^{(8)}$ Controller 450 User's Guide Load Calculation Forms

\section{Load Calculation}

\section{Load Calculation Forms}

\section{Table Calculation of CPU-load from S100 and S800 Inputs}

\begin{tabular}{|c|c|c|c|c|c|c|}
\hline Signal type & $\begin{array}{l}\text { No of } \\
\text { signals }\end{array}$ & $\begin{array}{l}\text { Basic load } \\
\text { (ms) }\end{array}$ & $\begin{array}{l}\text { Scan time } \\
\text { (ms) }\end{array}$ & $\begin{array}{l}\text { Dynamic load } \\
\text { (ms) }\end{array}$ & $\begin{array}{c}\text { Changes/sec. } \\
\text { per signal }\end{array}$ & Total load \\
\hline Al & A) & 0.20 & $\begin{array}{l}\text { C) } \\
\text { E) }=100^{*} A^{\top} B / C \\
\text { E) } \%\end{array}$ & 0.15 & 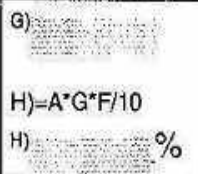 & $6=$ \\
\hline AIC & A) & 0.003 & $\begin{array}{l}\text { C) } m s \\
\text { E) }=100^{*} A^{2} B / C \\
\text { E) } \quad \%\end{array}$ & 0.08 & $\begin{array}{l}\text { G) } \\
\text { H) }=A^{*} G^{*} F / 10 \\
\text { H) } \quad \% \%\end{array}$ & $E+H$ \\
\hline DI cycl. & A) & $\begin{array}{l}\text { B) } 0.20 / \text { board } \\
\text { D) } \mathrm{ch} / \text { board }\end{array}$ & $\begin{array}{l}\text { C) } \\
\text { E) }=100^{*} A^{*} B / C / D \\
\text { E) } \quad \% \%\end{array}$ & 0.05 & $\begin{array}{l}\text { G) } \\
H)=A^{*} G^{*} F / 10 \\
\text { H) } \%\end{array}$ & $\begin{array}{l}\mathrm{E}+\mathrm{H} \\
\%\end{array}$ \\
\hline Dl interr. & $\begin{array}{l}\text { A) } \\
\text { and }\end{array}$ & & & 0.60 & $\begin{array}{l}G)=\frac{}{4} \\
H)=A^{*} G^{*} F / 10 \\
H)=\%\end{array}$ & $\%$ \\
\hline DIC & $\begin{array}{l}\text { A) } \\
\quad 3\end{array}$ & 0.003 & $\begin{array}{l}\text { C) } m s \\
\text { E) }=100^{*} A^{*} B / C \\
\text { E) } \%\end{array}$ & 0.05 & $\begin{array}{l}\text { G) } \\
H)=A^{*} G^{*} F / 10 \\
H) \%\end{array}$ & $\begin{array}{l}\mathrm{E}+\mathrm{H} \\
\quad \% \\
\end{array}$ \\
\hline & & & & \multicolumn{2}{|r|}{ Total } & 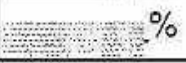 \\
\hline
\end{tabular}




\section{Appendix (B)}

Advant Controller 450 User's Guide

Load Calculation

Table Calculation of CPU-load from S100 and S800 Outputs

\begin{tabular}{|c|c|c|c|c|c|c|}
\hline Signal type & $\begin{array}{l}\text { No of } \\
\text { signals }\end{array}$ & $\begin{array}{l}\text { Basic load } \\
\text { (ms) }\end{array}$ & $\begin{array}{l}\text { Scan tlme } \\
\text { (ms) }\end{array}$ & $\begin{array}{l}\text { Dynamic load } \\
\text { (ms) }\end{array}$ & $\begin{array}{c}\text { Changes/sec. } \\
\text { per signal }\end{array}$ & Total load \\
\hline $\mathrm{AO}$ & A) & 0.02 & $\begin{array}{l}\text { C) } \mathrm{ms} \\
\text { E) }=100^{*} A^{*} B / C \\
\text { E) } \quad \%\end{array}$ & 0.18 & $\begin{array}{l}\text { (a) } \\
H_{j}=A^{*} G^{*} F / 10 \\
\text { H) } \%\end{array}$ & $\begin{array}{l}\text { E+H } \\
\end{array}$ \\
\hline$A O C$ & A) & 0.003 & $\begin{array}{l}\text { C) } \\
\text { E) }=100^{*} A^{*} B I C \\
\text { E) } \%\end{array}$ & 0.03 & $\begin{array}{l}\text { G) } \\
H)=A^{*} G^{*} F / 10 \\
\text { H) } \quad \%\end{array}$ & $\begin{array}{l}E+H \\
\%\end{array}$ \\
\hline DO & A) & 0.003 & $\begin{array}{l}\text { C) } m s \\
\text { E) }=100^{*} A^{*} B / C \\
\quad \%\end{array}$ & 0.13 & $\begin{array}{l}\text { G) } \\
\text { H) }=A^{+} G^{*} F / 10 \\
\text { H) } \%\end{array}$ & $\begin{array}{r}E+H \\
0 \%\end{array}$ \\
\hline DOC & A) & 0.003 & $\begin{array}{l}\text { C) } \mathrm{ms} \\
\text { E) }=100^{*} A^{*} B / C \\
\text { E) } \quad \%\end{array}$ & 0.03 & $\begin{array}{l}\text { G) } \\
\text { H) }=A^{*} G^{*} F / 10 \\
\text { H) } \quad \%\end{array}$ & 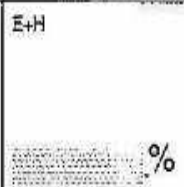 \\
\hline & & & & & Total & $\%$ \\
\hline
\end{tabular}

حساب حمل المحكمات لشبكة تحكم حاسويية باستخدام نظرية الاحتمالات

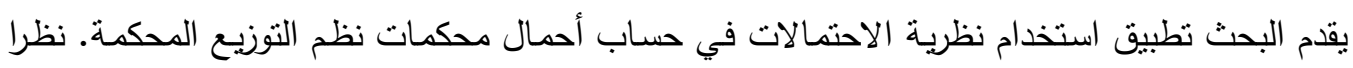
للتغير المستمر في حالة الوسط المطلوب التحكم فيه نستخدم نظريـة الاحتمالات في حساب أحمال

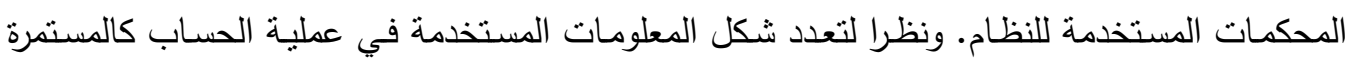
والمتقطعة أمكن تطبيق نظريـة الاحتمالات في حسـاب حمل المحكم. وقد أثتبت النتائج نقارب القيم المحسوبة باستخدام نظرية الاحتمالات مع القيمة المقاسة لحمل المحكم مما يبين أهية الطريقة المقترحة

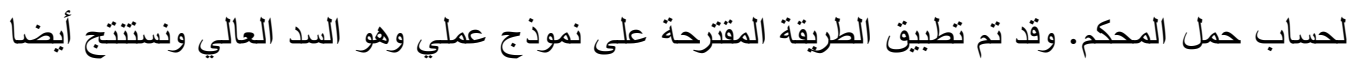

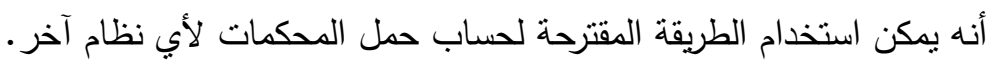

